\title{
Intimate Relationships as Routes into and out of Homelessness: Insights from a Canadian City
}

\author{
MARION E. JONES*, MICHEAL L. SHIER** and JOHN R. GRAHAM*** \\ * Professor, Department of Economics, University of Regina, Regina, SK, S4S OA2, Canada \\ email: marion.jones@uregina.ca \\ **Ph.D. Student, School of Social Policy and Practice, University of Pennsylvania; 3815 \\ Walnut Street, Philadelphia, Pennsylvania, USA, 19104-6106 \\ email: mshier@sp2.upenn.edu \\ ***Murray Fraser Professor of Community Economic Development, Faculty of Social Work, \\ University of Calgary, 2500 University Dr. NW, Calgary, AB, T2N 1N4, Canada \\ email: jrgraham@ucalgary.ca
}

\begin{abstract}
The literature on homelessness tends to focus on risk factors in people's social and personal lives that contribute to their situation of being without a permanent home. Alternatively, the following describes innate factors of intimate relationships that contribute to a situation of homelessness for men and women. We conducted interviews with 61 people experiencing homelessness in Calgary, Alberta, Canada. We were particularly interested in documenting with greater specificity their perceptions of their individual pathways to and from homelessness. Three themes emerged from the data describing the intersection between respondents' intimate relationships and their situation of homelessness: (1) relationship breakdown; (2) the role and impact of having intimate partners during a period of homelessness; and (3) the nature of the intimate relationship and its impact on housing. The data suggest that aspects of intimate relationships should be considered by social service agencies when addressing a person's situation of homelessness.
\end{abstract}

\section{Introduction}

There are two trends in housing supply and demand that directly impact the intimate relationship-homelessness nexus. First, the cost of both rental and owner-occupied housing in some cities has risen and there is a significant shortfall in supply (this was particularly true in the western Canada city that acted as the site of data collection in this study), the selling off and privatisation of social housing assets has aggravated this shortfall, and the widespread conversion of rental units to condominiums has resulted in the need to have more than one income to afford stable long-term housing. Second, the number of divorces and single adult households is on the rise (Statistics Canada, 2005, 2009), increasing the demand for housing, just as supply remains significantly constrained, particularly at the lower end (Human Resources and Skills Development Canada, 2011). This 
housing supply and demand dichotomy, however, is far too simplistic a picture, and a more holistic analysis is required to understand the dynamic between intimate relationships and homelessness.

This research is theoretically framed from assumptions inherent in the pathways approach to understanding homelessness ${ }^{1}$ (Clapham, 2002, 2003), which examines the ever-changing nature of homelessness and recognises a diversity of housing experiences. Following this approach, homelessness is recognised as an event on an individual's housing pathway. Housing pathways must be examined as dynamic sets of relationships (material and social) and interactions which the individuals in a household experience and negotiate individually and/or collectively during their consumption of housing. Housing is not consumed independently of other life pathways (social, family, employment), but rather runs alongside them, and is often intertwined with them (Clapham, 2002). Intimate relationships are a key part of the adult population's social and material pathways, and examining their aspects and impacts on housing is crucial to understanding the diverse experiences of homelessness (Nyamathi et al., 1999a; Nyamathi et al., 2001; Wesley and Wright, 2005). For the purposes of this analysis, intimate relationships include boyfriends/girlfriends, and commonlaw and married spouses. While respondents also described other social relationships that had an impact on their housing situation, we sought to analyse this particular type of relationship in greater detail. Based on the pathways framework of analysis, Chamberlain and MacKenzie (2006) identify two points of transition in an individual's 'homeless career' that are useful for framing the intersection between intimate relationships and housing instability. The first, family breakdown, is well addressed within the literature. The second, housing crisis, where both partners may be thrust into homelessness as a result of poverty or poverty-causing lifecycle events, such as the unexpected loss of employment, death or illness of a family member.

The primary discussions within the literature, though, remain focused on the implications of relationship breakdown as a leading cause of homelessness. For instance, the connection between intimate relationships and housing stability is generally presented as a single variable examining divorce or separation and the risk of these for homelessness (Calsyn and Roades, 1994; Fertig and Reingold, 2008; Herman et al., 1997; Lipman et al., 2004). Household structure, particularly the number of income earning adults, can provide a level of social support and protection against economic hardship. The dissolution of relationships (divorce or separation) may remove a vital source of support and may result in housing instability (Fertig and Reingold, 2008; Herman et al., 1997; Lipman et al., 2004). What is missing from the literature, by contrast, is the role of intimate partnerships within the situation of homelessness.

In a study conducted in 2008 and 2009 that sought to investigate a wide range of factors from the perspectives of employed people experiencing homelessness, 
different aspects of intimate relationships the respondents had prior to and/or during homelessness were one factor identified as contributing in both positive and negative ways to their current situation of homelessness. Employing a qualitative analytical lens, we were able to probe deeper into the nuances and roles of intimate relationships and peoples' present situations of homelessness.

More detailed analysis of the effect of relationship characteristics as an explanatory variable for homelessness is largely focused on female victims of domestic abuse (Baker et al., 2003; Benda, 2006; Fertig and Reingold, 2008; Steinbock, 1995). Fertig and Reingold (2008) found that homeless mothers with dependent children are more likely than housed mothers to have been abused by their children's fathers. Similarly, Benda (2006) found a connection between sexual or physical abuse at any point in the lifecycle and homelessness amongst female veterans. Often, the male population is generally not considered when examining the role of domestic abuse due to systematic under-reporting of incidences, but a number of studies have examined the connection between other forms of trauma and increased homelessness amongst males (Herman et al., 1997; Benda, 2006). Intimate partner abuse, for instance, is a traumatic experience that may contribute to the onset of male homelessness for some.

Other research has found that addiction issues often lead to housing crisis due to the cost of addiction as well as the incompatibility between addiction and maintaining steady employment (Devine and Wright, 1997). This was addressed directly in the literature by Caton et al. (2000) who found that homeless persons were more likely to report that those living in their former residence used drugs or drank heavily. While the connection between addiction issues and homelessness amongst the addicted is well established and explored within the literature (Caton et al., 1994; Caton et al., 2000; Devine and Wright, 1997; Fertig and Reingold, 2008), the risk to a partner's housing stability due to addiction issues is not.

Research on the relationship between intimate partnerships and the current situation or experience of homelessness is also neglected. In their study of homeless women, Nyamathi et al. (1999b) identified that women in nonconflictive relationships had greater psychological wellbeing and life satisfaction and less non-injection drug use than either single homeless women or homeless women in conflictive relationships. While a study by Wesley and Wright (2005) focused more heavily on negative relationships experienced by homeless women, some attention was paid to experiences recounted by study participants whose intimate partnerships were a source of support and stability even while experiencing housing instability. For these participants, their partners provided a sense of safety and connection during these unstable periods. Positive intimate partnerships may represent hope for survival of and escape from homelessness. This literature regarding intimate partnerships and homelessness largely ignores the experiences of homeless men. There is significant opportunity to contribute 
to the body of knowledge regarding the homeless population by examining the social relationships formed by both homeless men and women.

The analysis presented in this research seeks to remedy some of these omissions within the current literature. First, it provides a more indepth investigation of the intersection between intimate relationships and homelessness, particularly beyond domestic violence. Second, the findings seek to describe the differences between the experiences of male and female respondents. Third, it identifies ways in which these findings can be better incorporated into practice situations with people experiencing homelessness, contributing to our understanding of the complexity of the homeless situation.

\section{Methods}

One-to-one interviews were conducted between November 2008 and February 2009 with 65 people who identified themselves as being employed and homeless using homelessness services in Calgary, Alberta, Canada. Since four of the recorded interviews could not be transcribed, the final sample for coding consisted of 61 people ( 25 females and 36 males). All respondents were 18 years of age or older. The sample included single adults, adults in a relationship and both single adults and adults in a relationship with children, although single adults was the dominant group. Our reporting did not document the numbers in each category.

Social service organisations in Calgary that support people experiencing homelessness estimate that 60 per cent of the homeless population is employed in some capacity. Calgary is a major Canadian urban centre of one million residents located in a region that has been the epicenter of the Canadian oil industry. A booming oil and natural gas economy in Alberta has resulted in large numbers of individuals migrating from other provinces, and certainly Calgary has been a recipient of some of these new residents. In the two to three years leading up to the study, rental housing vacancy had decreased substantially - during some periods it remained less than 1 per cent. A further consequence of regional growth in Calgary and the province of Alberta were drastic increases in housing prices and a significant rise in the cost of rental housing. As might be expected, figures on the growth in Calgary's homeless population are staggering. In 2006, the number of people experiencing homelessness had grown to 3,436, a 740 per cent increase since 1994 (Laird, 2007). A count in 2008 estimated that 4,060 people were visibly homeless; that is, accessing emergency shelters or sleeping outside with no permanent residence of their own (Stroick et al., 2008).

Initially, we sought participants who were employed full-time. However, after the first interviews, we realised that limiting 'employed' status to full-time formal employment would not capture the relationship between employment and the respondents' present housing situation. The homeless situation directly 
affects the type (permanent or temporary) and nature (part-time, casual or fulltime) of employment available to people. We therefore extended our criteria to include more informal types of employment. Of the sixty-one participants whose interviews we were able to transcribe, fourteen were employed full-time, six part-time and twenty-five in casual or temporary situations. Many casual or temporary employees were working full-time but in different job locations and positions from one day to the next. One participant was self-employed, and fifteen were currently unemployed but had recent histories of full-time or part-time employment.

Data were collected using standard ethnographic techniques (Fetterman, 1998, 2008; Holstein and Gubrium, 1995; Patton, 1990; Seidman, 1991). A member of the research team conducted interviews in person using a semi-structured, open-ended interview guide. Each interview lasted approximately one hour. Questions prompted respondents to describe their housing, employment and job training history, identify factors affecting their present situation of homelessness including intimate relationships - and give their perspective on how being homeless affects other aspects of their lives - including intimate relationships. Participants were compensated for their time with a gift card for a local grocery store.

Data from the transcriptions and the interviewer notes taken throughout the interview process were analysed using qualitative methods. Analytic induction and constant comparison strategies (see Goetz and Lecompte, 1984; Glasser and Strauss, 1967) were used to detect patterns (see Cresswell, 2009; Fetterman, 2008) within the transcribed interviews - specifically, emergent themes (see Charmaz, 2000; Williams, 2008) that focused on factors that respondents identified as affecting their housing situation. After reading all the interviews and identifying common patterns and themes, the researchers then coded the themes and searched the data for instances of the same or similar phenomena. Finally, the data were translated into more general working hypotheses. To increase the dependability and consistency of the findings, these hypotheses were refined until all instances of contradictions, similarities and differences were explained. The entire research team worked collaboratively on this stage of the research to maintain the credibility criteria of the study.

Six main themes emerged from this analysis: (1) the social environment or communities of people affect their present housing situation; (2) various factors related to employment also affect housing, and vice versa; (3) aspects of intimate relationships can affect the housing situation of people who are employed; (4) there are turnaround points that lead into and out of the situation of homelessness for those who are employed; (5) perceptions of the present housing situation affect respondents and their situation of homelessness; and (6) there are systemic and institutionalised barriers that keep people homeless and vulnerable and temporarily employed. This paper explores one of the primary categories 
in which data were coded: the interaction between intimate relationships and housing stability. Data within each category were analysed further, following the same processes as described above, until all findings were coded. The findings discussed below are supported by quotations from the participants; however, these quotations are not exhaustive of participant contributions in each category. Participants are identified by a number in brackets directly following the quote.

\section{Findings}

Three themes emerged from the data of the 24 respondents who described aspects of their intimate relationships and their present situation of homelessness. These are: (1) relationships that breakdown put people at increased risk of homelessness - including break-ups and death of significant partners; (2) intimate partners provide help and direction for some people to get out of, or through, the situation of homelessness; and (3) specific aspects of relationships have an impact on housing. The gendered nature of each theme emerged during our analysis, which informs the organisation and discussion of the quotes below. The most immediate observation of gendered differences is that approximately two-thirds of the participants to identify an intimate relationship were women, while most of the male respondents made no reference to intimate partner relationships as an issue affecting their current situation of being homeless, even though they had relationships in the past.

\section{Relationship breakdown and the situation of homelessness}

Previous research has found that women become homeless more often than men as a result of socially based factors (in comparison with individually rooted issues such as addictions or mental health) (Tomas and Dittmar, 1995). In relation to intimate relationships, this research has pointed to relationship breakdown or family disputes as being leading factors that can impact a woman's pathway to homelessness. Some of the homeless women in our study had left a 'bad' relationship that resulted in becoming homeless. For this subset of the population, family breakdown is a direct contributing factor in their current situation. What defined the relationship as 'bad' varied amongst these women; for many it was violence (not limited to the physical). However for some, it was escaping a situation that inspired undesirable behavior of their own (e.g. drug use). For some of these women, becoming homeless was a better living situation than the one that was left.

I am a very independent woman. I fell back (into a situation of homelessness) because I was hooked up with the wrong guy and I didn't want to be around the drugs anymore. I worked all the time and my money was always going to him for his fix. So I walked out on him last week. He doesn't know where I am. I don't want to be around that. I don't want to be in that environment. I want to move forward and build something. (40) (Female, age 44) 
Another respondent similarly stated:

My boyfriend and I stayed at my mom's and he got a job while I went to school. We tried to clean up our lives and we eventually got a place down in (respondent states area of city she was living). Then my ex decided to get back into the habit because he was going through depression after his dad died and because his mom was dying on him. He started using crack and he started sneaking out at night to steal from cars. I said to myself, 'I can't do this with my daughter. I'm not doing this.' I gave him chance after chance and one day he brought crack into the house and I grabbed it out of his pocket and I threw it on the front lawn and I told him to get out and he didn't so we ended up getting into a fist fight. He took off so I took my daughter and my bags and I left. (10) (Female, age 18)

For these women, living in the shelter was a better choice/option considering the many negative elements of their previous living situations. These women became homeless to access other needed supports. We mention this as it challenges our perception of why people access emergency shelter and on-going homeless shelter services. We generally perceive that people access shelters as a last resort. While this may be the case - as some respondents did exhaust other options, others did not have these multiple options; it was not until some were homeless that they started to receive the supports they needed based on their individual experiences and their own personal goals.

A second catalyst identified by some of the female participants for relationship breakdown was a period of less suitable housing situations - i.e. living either with family or in a hostel. These participants highlight a progression of instability that often marks the life histories of experiencing homelessness.

I have used shelters in the past but it was never like this. [In one situation] I was moving and the other reason was because me and my kids' dad never got along. So I wanted to leave his place. We stayed with his mom, but I wanted to leave her place and get a new place. So I went to a shelter. I had no help so I had to do it by myself with my kids. (63) (Female, age 26)

Likewise, another respondent stated:

We (respondent and partner) were staying at the [respondent names hostel] down on [respondent names street address] and we started running out of money, so we looked into other shelters and one of the first people we met here in Calgary actually pointed us to the (respondent names shelter) and we came here. We stayed here for about two weeks and then we got a place and then he left me so I ended up having to leave with our baby and come back here. So I've been here for a week now. (21) (Female, age 19)

For other women, the breakdown of an intimate relationship led to difficulty in maintaining employment, which in turn led to the housing crisis. The link between intimate relationships and homelessness is complicated; it is not just about people being able to afford adequate housing after a relationship is ended.

I was in [respondent names local social housing organisation] and I had employment, but this guy trashed my house and then I got the blame for it because it was my place and it was my responsibility. He was one of my ex boyfriends and just very abusive and he trashed the place 
and I couldn't go to work after that. Then a couple of times I was late because of having to stay up late (because of partner) or I would get too depressed and I would just lose interest in my work. (53) (Female, age 26)

Interestingly, only one female participant offered an explanation for homelessness related to family breakdown that was almost solely for financial reasons.

My ex left me and I tried for a year to maintain the apartment we had all on my own. I lost my job because I hurt my back, then I got that job at the (respondent names place of employment) and that was just making my rent. I cut the cable, phone, all basics off. I was just paying rent. But it got behind and behind because I was late all the time because I couldn't keep making all the rent. They took me to court and then I had to pay court costs - that was more money on top of the rent every month. Finally they just came and changed the locks on me. (57) (Female, age 51)

The classic assumption that relationship breakdown leads to economic crisis for women and thus to the loss of housing is insufficient for the female population within this study. It was more common for the women in the study to experience homelessness as the alternative to a 'bad' relationship; their homelessness was directly and indirectly a response to their intimate relationship situation. Interestingly for the female population, contrary to popular culture stereotypes, homelessness for the majority represented regaining control rather than losing control over their lives and relationships. For those women, leaving a 'bad' relationship was a matter of taking back control of their lives, which was only possible by moving into an equally unstable situation. This differs from the following quotes by male participants; all of the male interviewees frame the situation of the relationship dissolution as being in their control, except in the case of the death of an intimate partner.

Men were more likely to report that they 'just walked away' (35) from a relationship and their material possessions. The language here is significant; while women indicated that something compelled them to exit a bad situation and regain control over their lives, the male participants were more likely to frame their experiences in terms of continued personal agency and choice. This gendered difference is important since the way in which a problem is framed affects the response to it. It becomes easy to ignore the role of intimate relationships in the housing situation of men because they view themselves as being in control of their relationships as opposed to the 'victim' or the 'controlled' as one sees with the female respondents.

I got an apartment with a girl out here, then we broke up so I gave her everything. I just left. In between that relationship I was living in my car. I hooked up with another girl and then we got a place together and that fell apart too. I just broke up with my last ex girlfriend and I gave her everything too, because she had kids and everything. Then I found myself on the streets. Living in my truck again. (4) (Male, age 29) 
Likewise, another male respondent described:

I caught her (respondents wife) with another guy so I just walked away. I grabbed the kids, packed them up, and then took them to their grandmother's place and I told them what happened. Her (respondent's wife) mother kicked her out and kept the kids. I know the kids will be safe with their grandmother. She bought me a ticket back out here and here I am. (35) (Male, age 35)

It is important to note when interpreting this analysis that common stereotypes of the active male and the passive female are not being promulgated. The interpretation of these quotes might lead a reader to believe that, but emphasis needs to be placed on the active component - both males and females are active in their relationship situations. Some have intentionally left negative situations seeking out help, and both men and women have been affected in some way (in particular in relation to their housing situation) negatively by their intimate relationships. Even though the relationship experiences are similar, the interpretation of how they are affecting individuals' lives is reported differently between males and females; a consideration that is important for service delivery personnel tasked with helping people back to stable housing.

For two male participants in our study, the loss of a spouse or partner triggered behaviours that later led to a housing crisis. Amongst these men, the death of a partner kicked-off a downward spiral that ended in homelessness. It is notable that these are the only occurrences in our research on interaction between intimate partnerships and homelessness in which men indicated or admitted to a lack of control over what happened in their lives and the effect that it had. This is crucial as it is the singular instance in which male participants indirectly identified a space for welfare service intervention in relation to personal relationships that may have prevented them from becoming homeless. This finding demonstrates that the death of a spouse and inadequate support and resources to deal with the grief can impact a person's housing situation.

I started gambling and started doing some heavy drinking after my wife died, and then lost my job. And things were getting depressed. I drank before that but not heavily. I didn't really gamble that much but gambled more. Just didn't want to be by myself. (25) (Male, age 48)

The other participant who described the loss of their spouse reported:

My mother passed away about 18 months after my wife did and I went into a kind of depression. They tell me I have a slight case of post-traumatic stress disorder. Then things just sort of. . that was about four years now. I had her living with us and there was a lot, she took a lot of looking after. After my wife had passed on she was diagnosed with lung cancer. So after she passed on I was just, I went into a depression; I was very, very tired. I worked sporadically since then. (13) (Male, age 53)

The experiences of the final participant are particularly telling of the limited social capital commanded by this population. Many people experiencing 
homelessness are from disjointed or broken family situations. The loss of a spouse may be indicative of the loss of one's only real social support network. For the final participant, the loss of both of the women he resided with, his wife and mother, may have been the complete loss of anywhere to turn to, and social accountability and support from anyone. Further, the cost of his mother's care following her illness (the Canadian universal healthcare system does not cover the substantial drug costs faced by cancer patients once they leave the hospital) was a lifecycle poverty event that led to a more financially precarious position that was compounded by no spousal income and sporadic employment after her death. This highlights another axis of vulnerability and systematic exclusion from housing through the nature of employment - those where compassionate care can be accommodated and those where it cannot (through the Canadian Employment Insurance program, all working people should have access to compassionate care leave, but in practice they do not).

\section{Intimate partners during a period of homelessness}

Intimate partners during a period of homelessness can also impact a person's housing situation. Intimate relationships have been shown to impact positive and negative behaviours of people experiencing homelessness (Loates and Walsh, 2010; Neaigus et al., 1994; Zapka, Stoddard, and McCusker, 1993). How, though, does the current homeless situation of a person affect their present intimate relationships? Previous research on homeless women has found that intimate relationships tend to be disrupted because of their situation of homelessness (Nyamathi et al., 1995). Alternatively, some of the female respondents indicated that the current period of housing instability had served to strengthen their relationships with their intimate partners. Their relationships were a key source of social support.

When we (respondent and intimate partner) were staying at the churches we registered as a couple. Women have priority at this shelter but I still chose to register as a couple because I didn't want to have a priority bed and then my partner by chance not get a bed and have to go somewhere else... So we registered as a couple and then if we didn't get a bed then we would go and stay at the (respondent names other shelter services). We would go stay there together. It is both of our first times being homeless so we wanted to stick together. (59) (Female, age 29)

Similarly, another respondent stated:

I wanted to get out of here but we can't because we have nowhere to go; we do not have money. It's just hard. I always get mad at him; sometimes I get so stressed out. Like when I talk like this, I always want to cry. But I think I'm getting [better], I always talk about my relationship; I always talk about it and then it helps. (22) (Female, age 36)

For many of the women, however, the crisis situation served to facilitate the end of their relationship. The loss of housing with their partners functioned as 
a 'wake-up call'. One woman who came to see her partner as a negative force in her life stated:

He is into hard drugs, and for the past two years of our relationship I was more or less supporting his drug habit. I got tired of him picking drugs over me. So for about two years, I kept trying to do whatever I could - trying to get him into treatment, I mean I was even willing to quit smoking pot and whatever else, do whatever I could, anything and everything I could. When I ended up coming back here (to the shelter), it was the end for me. No, I'm done, I can't support him; he didn't want to have a relationship without drugs, so I broke up with him. We were together almost five years. (28) (Female, age 35)

The men, like some of the women in our study, who spoke about their current intimate relationships saw their partners as a source of hope and a motivational factor to make a change. For these men, the continued relationship with their partners may represent a sense of normalcy and stability in their unstable lives.

I've got my family to worry about. That is what gives me hope. That is the only thing. Because I know if I didn't have them I'd be dead. No doubt in my mind I'd be dead. My wife and my kids are the only thing that keep me alive. (32) (Male, age 35)

Likewise, another respondent described:

It's just working on my fiancée and that right now, give her a good life that she never had the opportunity to have. That is important to me. (17) (Male, age 43)

This category of findings describes a useful place to start thinking about the impact of relationship dynamics on the situation of homelessness. Ethnographic research has shown that many people do not experience homelessness alone (Snow and Anderson, 1993; Wagner, 1993; Winchester and Costello, 1995). People experiencing homelessness form relationships with each other and with specific community members segregated from other elements of their local community. Another paper with data from this study provides an analysis of the overlap and implications that social communities have on employed people experiencing homelessness (Shier et al., 2011). These findings provide an alternative perspective for thinking about this particular type of situation. Including the impact of relationship dynamics (positive and negative) in service provision might make service delivery more adept at meeting the needs of the homeless population. At the very least, it would allow for service delivery to be more comprehensive in how it addresses the multiple risk factors that contribute to homelessness. Few shelters are set up to encourage or enable positive interpersonal relationships between shelter users - often these measures are to ensure safety in a co-ed situation to allow the development of more positive social relations, particularly more positive intimate partner relationships. Ideally, shelters would not be necessary, but considering the absence of a basic human right for housing and an ongoing decrease in available affordable housing, at the least shelters could be more adaptive in the type of services offered or available to people who are in ongoing 
intimate partner relationships. Making accommodations available to couples could have a positive impact on people's exit from homelessness. Further research in this area is necessary to explore the impact of intimate partner relationships on exiting homelessness.

\section{Nature of the relationship and the impact on housing}

Most research studies about women, their relationships, and housing situations typically point to issues of domestic violence and abuse - signifying these as primary risks that result in homelessness (Lehmann et al., 2007). Also, because of multiple claims made about needing a clearer understanding of the gendered context of homelessness, research has sought to explore the specific risk factors to homelessness that are unique to males and those unique to females (Zugazaga, 2008), or particular behaviours of homeless men and those of homeless women (Nichols and Ca'Zares, 2006). That research has led to useful suggestions for social policy and social programming. Homelessness, nevertheless, is a complex social issue that is based in part on interactions with other people and we cannot simply determine general risk factors that may or may not lead to homelessness. Instead, we need a more detailed understanding of how people are or are not interacting with each other to effectively resolve a person's, a couple's, or a family's situation of homelessness.

Our research highlights this point by illustrating how the nature of a relationship impacts a person's housing situation. For instance, from the previous excerpts a reader can determine that many relationships were negative and people left the stability of permanent housing without an alternative housing solution beyond sleeping in their vehicle or utilising shelters. For the respondents in this predicament, there were no other resources to help support them through this period of transition. Other respondents showed evidence of social capital -they had the ability to develop relationships with people while living in the shelters or maintained partnerships while homeless. Likewise, there was evidently enough support for the many people residing with friends or families - and not in shelters - after the breakdown of their intimate relationships.

Our respondents illustrated how the nature of their relationships impacted their housing situation. For instance, two of the female participants entered into intimate relationships and moved to join their partners with the expectation that their partner had a stable place to live. These women became in some ways 'accidentally' homeless, having entered into the situation unknowingly and with little to no prior warning that it was going to occur.

The guy that I was with wanted to come back to Calgary, he said that we could stay with his Dad - no problem. So I left my apartment and everything else behind and we got here, his Dad had no idea I was coming. He let us stay there for about a week and then he kicked us out. That is how I became homeless. It was not the first thing on my mind. I always managed to keep a roof over my head, keep my bills paid, keep my home until I met him. (28) (Female, age 35) 
One male participant recognised the nature of his relationship and his choice not to provide assistance to his partner, opting instead to temporarily improve his own situation. He does not deny the ethics of his choice and seems to have exited the relationship without informing the other party of the decision.

It is the relationship. I can't say we are soul mates but we're just stuck with each other. I love her and she loves me but we've done too many things to each other to where we're just, we have to deal with it finally. Like the right thing for me to do today would be not to get the hotel room, it would be to see her and give her some money and whatever, but, honestly I don't think I'm gonna do that. (31) (Male, age 29)

When we begin to consider the nature of relationships and their influence on homelessness we move discussions beyond a focus on risk factors. Future research could investigate the types and characteristics of relationships that do not lead to homelessness, or that lead to stable long-term housing solutions - pathways from homelessness. Intimate relationships need to be seen as both potential causes of and potential solutions to homelessness and stable housing.

\section{Discussion}

This research identifies a need to consider the interactions between intimate partnerships and housing stability beyond the variable of family breakdown as a cause of homelessness. By moving away from viewing the homeless as types of people (the addict, the mentally ill, the runaway, etc.) with particular risk factors, to examining homelessness as a process involving an interacting set of interpersonal relationships as is done here, a need to examine the social and family relationships of those who become homeless is evident. This focus aids in understanding both the possible causes and the experience of being homeless, thus allowing the development of more effective policy and service responses (Chamberlain and MacKenzie, 2006).

This research suggests the vital need for increased availability of stable emergency housing for those women leaving 'bad' relationships to prevent homelessness in the first place. This finding is not new to our study and is suggested in most examinations of the interaction between domestic violence and homelessness.

The chain of events from relationship breakdown or partner's death to depression, the inability to keep a job and the housing crisis experienced by both men and women within this study must be considered carefully. Significantly, this population experienced a rather lengthy window of need that, if addressed, may have prevented the housing crisis and loss of a home in the first place. The challenge is in identifying this population and addressing their needs prior to the ensuing crisis, which may be for many the first time they access social welfare services of any kind or come to anyone's attention. The gendered nature of the impacts of intimate relationships on housing stability further complicates the 
situation. The women in our study were more likely to indirectly identify areas for intervention by indicating their loss of control within a relationship. Conversely, the men in our study embodied the social stereotypes in which they were raised and, with the exception of those men whose spouses died, they maintained that they were ultimately in control of the relationship situation, thus no space for intervention with regard to intimate partner relationships was created. Perhaps most notably, our research found a considerable number of participants who clearly identified the positive role of their present intimate partnerships on their psychosocial well-being and their motivation to address those personal factors contributing to their ongoing situation of homelessness (including abstaining from drug use, and actively pursuing employment opportunities). This interaction is underexplored within the literature and deserves greater focus.

Putting these findings back into the discourse about 'pathways to housing' supports a model of service delivery that incorporates an assessment of a person's personal/intimate relationships. The forced asexuality that is part and parcel of most homeless shelters undermines a person's sense of self, acts as an undignified and inhumane aspect of shelter services and challenges the potential for positive social networks and intimate relationships in a systemic way. A set of assumptions about the humanness of people experiencing homelessness and what their overall needs encompass underlies the direction that social services take. Future research might investigate how practitioners address issues related to intimate relationships with clients and how they can improve practice to include the ideas provided by the employed homeless men and women who participated in our study.

\section{Conclusion}

This research seeks to illustrate the complex interaction between intimate relationships and housing stability amongst the employed homeless and expands beyond the single variable of family breakdown as a cause of homelessness. Intimate relationships are shown to interact with housing in both negative (leading to the loss of housing) and some positive ways within the homeless situation. Recognising the value of being in a positive relationship and forming a household unit to an individual experiencing homelessness can be necessary. Further, the diverse experiences of and pathways to homelessness due to 'bad' relationships must be considered in order to gain a broader understanding of the interactions between housing pathways and social/family pathways. Many shelters, intending to protect women who are seen as potentially vulnerable, maintain a strict policy of gender division. However, the potential for homeless people to build strong and positive networks of social capital and create important preconditions for a successful and lasting transition to housing is being undermined by a system that keeps people out of intimate relationships. Same-sex friendships are encouraged, but limited in the often unstable world of homeless 
shelter use; and even more substantial barriers exist for mixed-sex relationships, intimate or not, that might also serve to foster the transition to housing.

\section{Note}

1 For the purposes of this paper, homelessness is defined as being reliant on shelter services or services catering to those sleeping rough. We acknowledge that there is a significant population of people who are hidden homeless, but the fact that they have not yet exhausted their social capital, so that they remain hidden homeless, puts them in a different category from the population of visible homeless that we sampled.

\section{References}

Baker, C., Cook, S. and Norris, F. (2003), 'Domestic violence and housing problems: a contextual analysis of women's help-seeking, received informal support, and formal system response', Violence Against Women, 9: 7, 754-83.

Benda, B. B. (2006), 'Survival analyses of social support and trauma among homeless male and female veterans who abuse substances', American Journal of Orthopsychiatry, 76: 1, 70-9.

Calsyn, R. J. and Roades, L. A. (1994), 'Predictors of past and current homelessness', Journal of Community Psychology, 22: 3, 272-8.

Caton, C. L., Shrout, P. E., Eage, P. F. and Opler, L. A. (1994), 'Risk factors for homelessness among schizophrenic men: a case-control study', American Journal of Public Health, 84: 2, 265-70.

Caton, C. L., Hasin, D., Shrout, P. E., Opler, L. A., Hirshfied, S., Dominquez, B. and Felix, A. (2000), 'Risk factors for homelessness among indigent urban adults with no history of psychotic illness: a case-control study', American Journal of Public Health, 90: 2, 258-63.

Chamberlain, C. and MacKenzie, D. (2006), 'Homeless careers: a framework for intervention', Australian Social Work, 59: 2, 198-212.

Charmaz, K. (2000), 'Grounded theory: objectivist and constructionist methods', in N. K. Denzin and Y. S. Lincoln (eds.), Handbook of Qualitative Research, Thousand Oaks, CA: Sage Publications, pp. 509-35.

Clapham, D. (2002), 'Housing pathways: a post modern analytical framework', Housing, Theory and Society, 19: 2, 57-68.

Clapham, D. (2003), 'Pathways approaches to homelessness research', Journal of Community and Applied Social Psychology, 13: 2, 119-27.

Creswell, J. W. (2009), Research Design: Qualitative, Quantitative, and Mixed Methods Approaches (3rd edn), Thousand Oaks, CA: Sage Publications.

Devine, J. A. and Wright, J. D. (1997), 'Losing the housing game: the levelling effects of substance abuse', American Journal of Orthopsychiatry, 67: 4, 618-31.

Fertig, A. R. and Reingold, D. A. (2008), 'Homelessness among at-risk families with children in twenty American cities', Social Service Review, 82: 3, 458-510.

Fetterman, D. M. (1998), Ethnography: Step by Step, Thousand Oaks, CA: Sage Publications.

Fetterman, D. M. (2008), 'Ethnography', in L. M. Given (ed.), The Sage Encyclopedia of Qualitative Research Methods, Thousand Oaks, CA: Sage Publications, pp. 288-92.

Glasser, B. G. and Strauss, A. L. (1967), The Discovery of Grounded Theory: Strategies for Qualitative Research, New York: Aldine Press.

Goetz, J. P. and LeCompte, M. P. (1984), Ethnography and Qualitative Design in Educational Research, San Diego, CA: Academic Press.

Herman, D. B., Susser, E. S., Stuening, E. L. and Link, B. L. (1997), 'Adverse childhood experiences: are they risk factors for adult homelessness?', American Journal of Public Health, 87: 2, 249-55.

Holstein, J. A. and Gubrium, J. F. (1995), The Active Interview, Thousand Oaks: Sage Press.

Human Resources and Skills Development Canada (2011), Housing - Rental Vacancy Rates, Ottawa, ON: Government of Canada, retrieved 2 June 2011, http://www4.hrsdc.gc. ca/.3ndic.1t.4r@-eng.jsp?iid=43. 
Laird, G. (2007), Shelter: Homelessness in a Growth Economy - Canada's 21st Century Paradox, Calgary: Sheldon Chumir Foundation for Ethics in Leadership.

Lehmann, E. R., Kass., P. H., Drake, C. M. and Nichols, S. B. (2007), 'Risk factors for first-time homelessness in low-income women', American Journal of Orthopsychiatry, 77: 1, 20-8.

Lipman, B., Mirabelli, F. and Rota-Bartelink, A. (2004), Homelessness among Older People: A Comparative Study in Three Countries of Prevention and Alleviation, Melbourne: Wintringham.

Loates, M. and Walsh, C. A. (2010), 'Women negotiating sexual identity in the face of homelessness: from silence to satisfaction', Culture, Health, and Sexuality, 12: 10, 87-101.

Neaigus, A., Friedman, S., Curtis, R., DesJarlais, D., Furst, R., Jose, B., Mota, P., Stephenson, B., Sufian, M. and Ward, T. (1994), 'The relevance of drug injectors and risk networks for understanding preventing HIV infection', Social Science and Medicine, 38: 67-78.

Nichols, L. and Ca'Zares, F. (2006), 'Homelessness and the mobile shelter system: public transportation as shelter', Journal of Social Policy, 40: 2, 333-50.

Nyamathi, A., Bennett, C., Leake, B. and Chen, S. (1995), 'Social support among impoverished women', Nursing Research, 44: 376-8.

Nyamathi, A., Galaif, E. R. and Leake, B. (1999a), 'A comparison of homeless women and their intimate partners', Journal of Community Psychology, 27: 4, 489-502.

Nyamathi, A., Wenzel, S., Keenan, C., Leake, B. and Gelberg, L. (1999b), 'Associations between women's intimate relationships and their health and well-being', Research in Nursing and Health, 22: 6, 486-95.

Nyamathi, A., Wenzel, S., Lesser, J., Flaskerud, J. and Leake, B. (2001), 'Comparison of psychosocial and behavioral profiles of victimised and nonvictimised homeless women and their intimate partners', Research in Nursing and Health, 24: 324-35.

Patton, M. Q. (1990), Qualitative Evaluation and Research Methods (2nd edn), Newberry Park, CA: Sage Publications.

Seidman, I. E. (1991), Interviewing as Qualitative Research: A Guide for Researchers in Education and the Social Sciences, New York: Teachers College Press.

Shier, M. L., Jones, M. E. and Graham, J. R. (2011), 'Social communities and homelessness: a broader concept analysis of social relationships and being homeless', Journal of Human Behavior in the Social Environment, 21: 5, 455-74.

Snow, D. A. and Anderson, L. (1993), Down on Their Luck: A Study of Homeless Street People, Berkeley, CA: University of California Press.

Statistics Canada (2005), Divorces, Ottawa, ON: Government of Canada, retrieved 2 June 2011 from: http://www.statcan.gc.ca/daily-quotidien/050309/dq050309b-eng.htm

Statistics Canada (2009), 2006 Census: Family portrait - Continuity and Change in Canadian Families and Households in 2006, National portrait, Households. Ottawa, ON: Government of Canada, retrieved 2 June 2011, http://www12.statcan.ca/census-recensement/2006/assa/97-553/p8-eng.cfm

Steinbock, M. (1995), 'Homeless female-headed families: relationships at risk', Marriage and Family Review, 20: 1-2, 143-59.

Stroick, S. M., Hubac, L. and Richter-Salomons, S. (2008), Biennial Count of Homeless Persons in Calgary: 2008 May 1, Calgary: The City of Calgary, Community and Neighborhood Services, Social Research Unit, retrieved 12 July 2009, http://content.calgary.ca/CCA/ City \pm Hall/Business \pm Units/Community \pm and \pm Neighbourhood \pm Services/Social \pm Research \pm Policy \pm and \pm Resources/Affordable \pm Housing \pm and \pm Homelessness/Biennial \pm Count \pm of \pm Homeless \pm Persons.htm

Tomas, A. and Dittmar, H. (1995), 'The experience of homeless women: an exploration of housing histories and the meaning of home', Housing Studies, 10: 4, 493-516.

Wagner, D. (1993), Checkerboard Square: Culture and Resistance in a Homeless Community, Boulder, CO: Westview Press.

Wesley, J. and Wright, J. (2005), 'The pertinence of partners: examining intersections between women's homelessness and their adult relationships',American Behavioral Scientist, 48: 8, 1082-101. 
Williams, J. P. (2008), 'Emergent themes', in L. M. Given (ed.), The Sage Encyclopedia of Qualitative Research Methods, Thousand Oaks, CA: Sage Publications, pp. 248-9.

Winchester, H. P. M. and Costello, L. N. (1995), 'Living on the street: social organisation and gender relations of Australian street kids', Environmental Planning, Society and Space, 13: $329-48$.

Zapka, J., Stoddard, A. and McCusker, J. (1993), 'Social network, support and influence: relationships with drug use and protective AIDS behavior', Aids Education and Prevention, 5:352-66.

Zugazuga, C. B. (2008), 'Understanding social support of the homeless: a comparison of single men, single women, and women with children', Families in Society, 89: 3, 448-56. 